\title{
A vacinação contra a COVID-19 pode ser compulsória no Brasil? A questão jurídica e a disputa política
}

\section{Can the vaccination against COVID-19 be compulsory in Brazil? The legal issue and political dispute}

\author{
Carol de Oliveira Abud* \\ Luciano Pereira de Souza iD
}

Universidade Santa Cecília (Unisanta), Santos, SP, Brasil

\footnotetext{
* E-mail: abudcarol@hotmail.com
}

Recebido: 08 jan 2021

Aprovado: 19 jul 2021

\begin{abstract}
RESUMO
Introdução: A recente celeuma em torno da COVID-19 paira sobre os direitos e deveres da população frente à vacinação e a imunização em massa. 0 exercício da liberdade individual e a eventual imposição de medida que torna compulsória a vacinação podem estar no foco de uma disputa política em torno da adoção de critérios científicos para a tomada de decisões governamentais que poderão trazer sérias consequências coletivas em relação à propagação e ao descontrole da doença. Objetivo: Estudar se a vacinação compulsória contra a COVID-19, uma vez instituída por lei ou ato normativo, terá fundamentação jurídica em face dos direitos fundamentais e analisar se a disputa política em torno da vacina pode estar influenciando a sua normatização. Método: Estudo exploratório e descritivo elaborado por meio de pesquisa documental e bibliográfica, coleta de textos provenientes da Organização Mundial da Saúde, do Ministério da Saúde, do governo federal, do estado de São Paulo, da análise da legislação pátria e de decisões recentes do Supremo Tribunal Federal. Resultados: Observou-se que é possível estabelecer a vacinação compulsória no Brasil assegurando os direitos fundamentais, entretanto, questões políticas estão influenciando a tomada de decisões pautadas por critérios técnico-científicos de Vigilância Sanitária. Conclusões: A restrição da liberdade individual encontra amparo no fundamento de busca pela saúde de interesse coletivo, desde que não extrapole os limites da integridade física do cidadão e da dignidade humana, vedado o uso da coerção física. A disputa política encabeçada por alguns agentes públicos pode ter acarretado atrasos e retrocessos na imunização vacinal da população brasileira, forma eficaz de controle da pandemia.
\end{abstract}

PALAVRAS-CHAVE: Direito à Saúde; Infecções por Coronavírus; Saúde Pública; Programas de Imunização; Recusa de Vacinação

\section{ABSTRACT}

Introduction: The recent uproar around COVID-19 hangs over the rights and duties of the population regarding vaccination and mass immunization. The exercise of individual freedom and the possible imposition of a measure that makes vaccination compulsory may be the focus of a political dispute around the adoption of scientific criteria for government decision-making, and with that, bring serious collective consequences in relation to the spread and the lack of control of the disease. Objective: To study whether compulsory vaccination against COVID-19, once instituted by law or normative act, will have a legal basis in view of fundamental rights and analyze whether the political dispute around the vaccine may be influencing its regulation. Method: Exploratory and descriptive study developed through documentary and bibliographic research, collection of texts from the World Health Organization, Ministry of Health, federal government and the state of São Paulo, analysis of national legislation and recent decisions by the Supreme Court. Results: It was observed that it is possible to establish compulsory vaccination in Brazil, ensuring fundamental rights; however, political issues are influencing decision-making based on technical-scientific criteria for health surveillance. Conclusions: The restriction 
of individual freedom finds support in the search for health in the collective interest, as long as it does not go beyond the limits of the physical integrity of the citizen and human dignity, the use of physical coercion being prohibited. The political dispute led by some public agents may have caused delays and setbacks in the vaccination of the Brazilian population, an effective way to control the pandemic.

KEYWORDS: Right to Health; Coronavirus Infections; Public Health; Immunization Programs; Vaccination Refusal

\section{INTRODUÇÃO}

A Organização Mundial da Saúde (OMS), frente ao surgimento da doença causada pelo novo coronavírus, corona virus disease ou COVID-19, relatada em fins de 2019'1 declarou, em 30 de janeiro de 2020, Emergência de Saúde Pública de Importância Internacional (ESPII) ${ }^{2}$, em razão do surto dessa doença em diversos países. Poucas semanas depois, no dia 11 de março de 2020, a OMS declarou situação de pandemia da doença ${ }^{3}$. Iniciou-se, com isso, uma batalha global contra a doença, já que o vírus passou a circular em escala mundial.

De acordo com o Coronavirus Resouce Center, da Universidade Johns Hopkins, do início dos casos relatados até 7 de janeiro de 2021 , data em que se realizou a coleta de dados do presente trabalho, o mundo acumulou um total de 87.434.105 casos confirmados de COVID-19, sendo que destes, 1.889 .952 pessoas vieram a óbito ${ }^{4}$.

No Brasil, os números oficialmente divulgados pelo Ministério da Saúde até a mesma data totalizavam 7.873.830 casos de COVID-19, sendo 198.974 pessoas falecidas em razão da doença ${ }^{4,5}$.

Deduz-se desses dados que o Brasil responde por 10,52\% das mortes causadas pela COVID-19 no mundo, enquanto sua população representa apenas $2,71 \%$ da população mundial ${ }^{6,7}$.

Durante esses meses, desde a instalação do estado pandêmico até hoje, a comunidade científica internacional e nacional passou a buscar por meio de estudos uma forma de conter a doença. Inicialmente, as medidas não farmacológicas foram mundialmente adotadas, com orientação da própria OMS. Medidas como: distanciamento social, higienização constante das mãos com álcool em gel ou sabão e uso de máscara facial caseira ou medicinal foram as decisões profiláticas acertadas até o momento ${ }^{8}$.

Em que pese a adoção certeira dessas medidas de profilaxia, o que se espera é a descoberta de uma (ou várias) vacina imunizante eficaz e segura.

Os cientistas correram atrás desse objetivo e, em tempo recorde, - assim considerado para a ciência - chegaram às etapas finais dos testes das vacinas ${ }^{9}$, algumas já com eficácia alcançada de até $97 \%$.

As vacinas de vários laboratórios e países, quando aprovadas pelo controle nacional sanitário de cada país, são introduzidas nas respectivas comunidades, o que já ocorreu em pelo menos 47 países (até 8 de janeiro de 2021, momento da submissão deste artigo). Para isso, contudo, é necessário um planejamento eficaz de vacinação da população. Cada país deverá orientar a imunização de sua população por meio desse planejamento ${ }^{10}$.
No Brasil, dois grandes e renomados centros de pesquisa que há anos produzem vacinas para uso do Programa Nacional de Imunizações (PNI) participam no processo de busca pela vacina: o Instituto Butantan, em São Paulo, em parceria com o laboratório Sinovac Life Science, com a vacina Coronavac ${ }^{11}$, e a Fundação Oswaldo Cruz (Fiocruz), no Rio de Janeiro, que trabalha em parceria com o laboratório AstraZeneca/Universidade de Oxford $^{12}$, com a vacina CHADOX1 NCOV-19, e que participa da coordenação dos ensaios clínicos de várias vacinas, entre elas, a própria Coronavac ${ }^{13}$.

Até o encerramento da pesquisa, quatro vacinas estavam oficialmente em teste no Brasil: as duas acima mencionadas, com transferência de tecnologia, a vacina do laboratório Pfizer-Wyeth (vacina BNT162) e a do laboratório Janssen-Cilag (vacina AD26. COV2.S), sem a transferência de tecnologia local ${ }^{14}$. A qualquer momento, outras novas vacinas poderão ser submetidas à Agência Nacional de Vigilância Sanitária (Anvisa).

Uma vez finalizada a etapa de testes pelos laboratórios e cumprido todo o protocolo exigido, havendo a autorização da agência reguladora (Anvisa), os imunizantes estarão aptos a serem distribuídos e até comercializados no Brasil. Contudo, para que ocorra a aplicação do imunizante na população de forma gratuita e garantida pela União através do Sistema Único de Saúde (SUS), há a necessidade de estratégia governamental, em forma de norma infralegal e planejamento.

O presente estudo visa analisar a viabilidade jurídica da compulsoriedade da vacinação no âmbito do necessário planejamento vacinal contra a COVID-19 no Brasil e avaliar se a disputa política ou politização em torno da vacina pode estar influenciando a sua normatização, uma vez que atribuir caráter político (ideológico e eventualmente eleitoral) à questão da imunização compulsória pode afastar o Estado da tomada de decisões pautadas em critérios técnico-científicos de Vigilância Sanitária.

\section{MÉTODO}

Para atingir os objetivos realizamos pesquisa exploratória e descritiva por meio da coleta de textos provenientes da OMS, do Ministério da Saúde, do governo federal, do estado de São Paulo, da legislação pátria e de decisões recentes do Supremo Tribunal Federal (STF).

Para a análise normativa adotamos o método técnico-jurídico, baseado na interpretação do conteúdo das normas jurídicas e demais formas de expressão do direito, inclusive e especialmente as recentes decisões do STF nas Ações Diretas de 
Inconstitucionalidade (ADI n 6.586 e ADI n 6.587) e no Recurso Extraordinário com Agravo (ARE $n^{\circ} 1267879$ RG), que tratam da vacinação obrigatória contra a COVID-19 e da obrigatoriedade de imunização vacinal de crianças e adolescentes em conformidade com o PNI.

Descrevemos as ações estatais na esfera federal e os marcos normativos que levaram à previsão da vacinação compulsória como medida de enfrentamento à COVID-19, partindo da linha do tempo da declaração do estado de ESPII pela OMS.

Examinamos o PNI atual e traçamos um breve comparativo com o plano de vacinação apresentado na pandemia do vírus influenza A H1N1 para deduzirmos a necessidade de planejamento logístico e inclusão do planejamento na política nacional de vacinação, considerando a gravidade da doença e o risco de propagação.

Examinamos o Regulamento Sanitário Internacional (RSI) e suas implicações junto aos países membros da OMS, que pretendem prevenir a propagação e controlar a doença, fundamentado nos princípios de direitos humanos e nas liberdades individuais.

Consideramos os principais aspectos constitucionais da aplicação da técnica da ponderação ou juízo de proporcionalidade sobre a vacinação compulsória como medida que atinge a liberdade individual de autodeterminação, tomando por base os direitos individuais e os direitos coletivos frente à caracterização pandêmica da doença. Delineamos as medidas necessárias face à saúde individual e coletiva no direito sanitário, atentando para os direitos humanos e os impactos que possam causar à coletividade.

Avaliamos possíveis influências de ordem política, pautadas por convicções ideológicas, posto que formadas sem embasamento em evidências científicas, na definição por parte do governo federal e demais entes federativos a respeito do caráter compulsório ou não da imunização vacinal contra a COVID-19.

Por fim, observamos os direitos individuais e coletivos e traçamos paralelo com a revolta da vacina para estabelecer sua ligação em relação ao posicionamento político no atual cenário de polarização vivido, sugerindo as consequências advindas da hesitação em vacinar.

O trabalho não se propõe a fazer análise bioética da imunização vacinal, como também não se propõe a discutir a questão cultural envolvida no chamado movimento antivacina.

\section{RESULTADOS E DISCUSSÃO}

Com a declaração da situação de ESPII ${ }^{2}$ por parte da OMS, o RSI ${ }^{15}$ passou a exigir dos países signatários o fornecimento de informações, a permanente avaliação de riscos e a notificação à OMS dos casos de COVID-19.

O RSI é um instrumento jurídico internacional que conta com a adesão de 194 países (estados-membros da OMS), instituído com a finalidade de ajudar a comunidade internacional a prevenir e responder a graves riscos de saúde pública que tenham o potencial de atravessar fronteiras.
O RSI também exige dos países participantes o desenvolvimento de capacidades, estruturas e serviços de vigilância e de resposta a eventos de saúde pública atualizados e condizentes com a situação do momento.

O Brasil é um dos países membros da OMS e aprovou ${ }^{16}$ o RSI proposto na $58^{\mathrm{a}}$ Assembleia Geral da OMS, por meio do Decreto Legislativo $n^{\circ} 395$, de 9 de julho de 2009.

Quando a OMS declarou a ESPII ${ }^{2}$ em 30 de janeiro de 2020, os países membros foram notificados para que tomassem as medidas $\mathrm{e}$ adequações necessárias para o risco sanitário que poderia surgir como consequência do novo coronavírus. Na mesma data, o Brasil atendeu ao chamamento da OMS e, por meio do Decreto $\mathrm{n}^{\circ} 10.212$, de 30 de janeiro de 2020 , promulgou a revisão do texto do RSI ${ }^{17}$.

Em 3 de fevereiro de 2020, o Ministério da Saúde, sob comando do ministro Luiz Henrique Mandetta, atendendo ao Decreto recém-promulgado e sabendo da defasagem da legislação em vigor à época, prontamente elaborou o anteprojeto de lei sobre as medidas para enfrentamento da ESPII decorrente do coronavírus $^{18}$. 0 documento foi encaminhado à apreciação presidencial e, posteriormente, tornou-se o Projeto de Lei $n^{\circ} 23 / 2020^{19,20}$.

Em 6 de fevereiro de 2020, o Projeto de Lei foi aprovado pelo Congresso Nacional em caráter de urgência ${ }^{20}$ e convertido na Lei $n^{\circ} 13.979$, que dispõe sobre as medidas para enfrentamento da ESPII decorrente do coronavírus responsável pelo surto de $2019^{21}$. É possível observar até então que o Ministério da Saúde passou a agir antes mesmo que a OMS declarasse o estado pandêmico, a partir do reconhecimento do surto da doença.

A Lei Federal $n^{\circ} 13.979 / 2020$, com suas respectivas alterações e acréscimos, estabelece que, para enfrentamento da ESPII, as autoridades poderão adotar, dentro de suas competências, medidas compulsórias tais como a vacinação (no artigo $3^{\circ}$, inciso III, d) ${ }^{21}$. Estabelece, ainda, que tais medidas compulsórias do artigo $3^{\circ}$ somente serão tomadas com base em evidências científicas e em análises sobre as informações estratégicas em saúde, devendo ser limitadas no tempo e no espaço ao mínimo indispensável à promoção e à preservação da saúde pública (artigo $\left.3^{\circ}, \S 1^{\circ}\right)$. E assegura às pessoas afetadas pelas medidas o pleno respeito à dignidade, aos direitos humanos e às liberdades fundamentais das pessoas (artigo $3^{\circ}, \S 2^{\circ}$, III), conforme preconiza o artigo $3^{\circ}$ do RSI ${ }^{15}$.

O RSI tem como princípios o respeito à dignidade, aos direitos humanos e às liberdades fundamentais das pessoas, em obediência à Carta das Nações Unidas e à Constituição da Organização Mundial da Saúde (artigo $3^{\circ}$ ). 0 documento estabelece como meta a proteção universal de todos os povos do mundo contra a propagação internacional de doenças. Por fim, o artigo ainda esclarece que os estados-membros possuem o direito soberano de legislar e implementar a legislação a fim de cumprir suas próprias políticas de saúde ${ }^{15}$.

O governo federal, até meados de abril de 2020, sob orientação do Ministério da Saúde, tomou decisões rápidas no início e até mesmo antes da pandemia ser declarada, agindo com base em evidências 
científicas. Entretanto, em meio a um momento crítico da doença (em abril de 2020), o médico Luiz Henrique Mandetta foi exonerado do cargo de ministro ${ }^{22}$, sendo nomeado o médico Nelson Teich para o Ministério da Saúde ${ }^{23}$. Após um mês da nomeação e com os casos de mortes e infecções em plena ascendência, o ministro pediu exoneração ${ }^{24} \mathrm{e}$, após um período sem ministro no comando do Ministério da Saúde, o general do Exército, Eduardo Pazzuello, assumiu como interino (em junho de 2020) ${ }^{25}$. 0 ministro foi nomeado oficialmente apenas em 14 de setembro ${ }^{26}$ e, até a data da elaboração deste artigo, permanecia no cargo.

A partir dessa última troca de ministros, o sistema de informações sobre os números da COVID-19 do Ministério da Saúde passou por uma drástica modificação. A transparência nas informações já não era tão clara e as ações não tão rápidas quanto eram inicialmente $e^{27,28,29}$.

Frente a isso e não havendo manifestação do governo federal sobre a estratégia e planejamento da futura vacinação, o Tribunal de Contas da União (TCU), fundado no entendimento de que o plano de vacinação é uma medida obrigatória de compromisso do Brasil, recomendou à Casa Civil da Presidência (em conjunto com o Ministério da Saúde) que elaborasse um plano de imunização para o Brasil ${ }^{30}$.

A recomendação do TCU veio em agosto de 2020, por meio do acórdão do relator ministro Vital do Rêgo (Acórdão $\mathrm{n}^{\circ}$ 2.092/2020), com o objetivo de avaliar e acompanhar a governança (inclusive e principalmente no planejamento dos gastos para a produção e aquisição das futuras vacinas e demais insumos) ${ }^{30}$ durante o enfrentamento da COVID-19. Em novembro de 2020, o governo federal recorreu da decisão do TCU.

Ao mesmo passo, no STF, duas ADI de posições antagônicas sobre a vacinação foram distribuídas: a de $n^{\circ} 6.586$ e a de $n^{\circ} 6.587$, ambas de relatoria do ministro Ricardo Lewandowski ${ }^{31,32}$. A de número 6.587, pretendendo o reconhecimento dos estados e municípios para determinar a vacinação compulsória da população e a análise de competência das autoridades e dos estados para tomarem medidas referentes à vacinação e a outra, pretendendo a declaração de inconstitucionalidade da compulsoriedade prevista na Lei $n^{\circ}$ 13.979/2020. Uma terceira demanda, por meio de Arguição de Descumprimento de Preceito Fundamental (ADPF $\left.\mathrm{n}^{\circ} 754\right)^{31,32,33}$, também do mesmo relator, pede que o governo federal apresente um plano de vacinação para o enfrentamento da doença e que possa fazer parte do $\mathrm{PNI}^{34}$. Outras ações e outras arguições foram distribuídas ao longo do mês de novembro e de parte de dezembro, algumas absorvidas para o julgamento destas e outras julgadas em sentido semelhante.

Em 24 de novembro de 2020, o ministro relator, em seu voto na ADPF $n^{\circ} 754$, determinou que o governo federal apresentasse, em 30 dias, um plano detalhado de vacinação contra a doença e que atualizasse o plano em questão a cada 30 dias, até o final do ano de 2021, e submetesse o plano ao Congresso Nacional para fiscalização e controle.

O governo federal apresentou em 12 de dezembro de 2020 um plano nacional de vacinação ${ }^{35}$ e, diante disso, o ministro relator do STF solicitou esclarecimentos sobre o plano apresentado, notadamente em relação à “(...) previsão de início e término do Plano Nacional de Operacionalização da Vacinação contra a COVID-19, inclusive de suas distintas fases". Prestadas as informações por petição juntada em 15 de dezembro de 2020 no mesmo dia, o ministro Lewandowski determinou a sua ampla divulgação e a cientificação do Congresso Nacional ${ }^{31,32,33}$.

De acordo com as informações prestadas pelo Ministro da Saúde: "O Ministério da Saúde estima que no período de doze meses concluirá a vacinação da população em geral, o que dependerá, concomitantemente, do quantitativo de imunobiológico disponibilizado para uso, completando-se o plano de vacinação em um total de aproximadamente dezesseis meses" (documento dos autos da ADPF $n^{\circ} 754$ ), ressaltando que:

até o presente momento, ainda não há vacina disponível para uso imediato no mercado brasileiro, o que, por evidente, é condição para disponibilização da vacina. Ademais, a incorporação de uma vacina ao Calendário Nacional de Vacinação dependerá da aprovação do imunobiológico pela Agência Nacional de Vigilância Sanitária (Anvisa), por processo de submissão regular ou emergencial.

Ou seja, o Ministério estabeleceu o prazo (intervalo de tempo) para vacinar a população, mas ainda não foi possível precisar a data de início da vacinação (até aquele momento) ${ }^{35}$.

0 processo que busca exigir judicialmente do governo federal um plano de imunização não é objeto desta pesquisa, mas releva destacar que continua em curso e pendente de julgamento (até o encerramento da pesquisa), sendo que no dia 29 de dezembro foi requerida tutela provisória incidental para “(...) que seja determinada à União (Poder Executivo Federal - Ministério da Saúde) a apresentação semanal da evolução nas tratativas de aquisição de todas as vacinas disponíveis listadas pela OMS, sendo a primeira em um prazo máximo de 48 horas”31,32,33.

Já em relação à vacinação compulsória, objeto do presente trabalho, em 16 de dezembro de 2020, o voto do ministro relator nas ADI foi a favor da compulsoriedade da vacinação, esclarecendo que vacinar ou não vacinar não é uma opção, admitindo restrições permitidas na Constituição Federal (CF) com interpretação conjunta com a Lei $n^{\circ} 13.979 / 2020$. Afirmou em voto que a competência dos estados é concorrente com a da União para elaborar medidas acerca da vacinação.

Realizados os julgamentos das ADI e do Recurso Extraordinário (tema 1103 de Repercussão Geral - ARE 1267879 RG) ${ }^{36}$, que interessam de plano ao presente estudo, pois discutem a questão formulada pela pesquisa, foram fixadas as seguintes teses vinculantes (que exigem a observância por parte de todos os órgãos estatais e pessoas em território nacional):

(I) A vacinação compulsória não significa vacinação forçada, porquanto facultada sempre a recusa do usuário, podendo, contudo, ser implementada por meio de medidas indiretas, as quais compreendem, dentre outras, a restrição ao exercício de certas atividades ou à frequência de determinados lugares, desde que previstas em lei, ou dela decorrentes, 
e (i) tenham como base evidências científicas e análises estratégicas pertinentes, (ii) venham acompanhadas de ampla informação sobre a eficácia, segurança e contraindicações dos imunizantes, (iii) respeitem a dignidade humana e os direitos fundamentais das pessoas, (iv) atendam aos critérios de razoabilidade e proporcionalidade e (v) sejam as vacinas distribuídas universal e gratuitamente; e (II) tais medidas, com as limitações acima expostas, podem ser implementadas tanto pela União como pelos Estados, Distrito Federal e Municípios, respeitadas as respectivas esferas de competência.

Esta tese foi fixada no julgamento da $A D I n^{\circ} 6.587$, que discutia a constitucionalidade do artigo $3^{\circ}$, III, d, da Lei $n^{\circ} 13.979 / 2020$, que prevê a obrigatoriedade da vacinação compulsória. Por meio dessa decisão, o STF por maioria julgou parcialmente procedente a ação para dar ao texto legal questionado interpretação conforme a $\mathrm{CF}$, reconhecendo a admissibilidade da vacinação compulsória, nos limites e nos termos fixados pela tese de julgamento acima reproduzida ${ }^{32}$.

Da mesma forma, em sua parte final, a tese resolveu o questionamento da $A D I n^{\circ} 6.586$ a respeito da competência do ente federativo para estabelecer a obrigatoriedade da vacina, estabelecendo que todos os entes da federação podem instituir a vacinação compulsória "respeitadas as respectivas esferas de competência" ${ }^{31}$.

Finalmente, com relação à pleiteada recusa dos pais ou responsáveis em promover a vacinação dos seus filhos menores ${ }^{36}$, foi estabelecida a seguinte tese de julgamento, servindo o caso como precedente judicial (leading case):

É constitucional a obrigatoriedade de imunização por meio de vacina que, registrada em órgão de Vigilância Sanitária, (i) tenha sido incluída no Programa Nacional de Imunizações ou (ii) tenha sua aplicação obrigatória determinada em lei ou (iii) seja objeto de determinação da União, Estado, Distrito Federal ou Município, com base em consenso médico-científico. Em tais casos, não se caracteriza violação à liberdade de consciência e de convicção filosófica dos pais ou responsáveis, nem tampouco ao poder familiar.

Diante do embate e das decisões judiciais, abordamos o problema da pesquisa em três tópicos: o primeiro descreve o conflito entre direitos fundamentais decorrentes da compulsoriedade da vacinação; o segundo descreve o plano de vacinação e a necessidade de estratégia prévia para aplicação das vacinas e o terceiro tratará de eventuais consequências do posicionamento político frente aos aspectos que envolvem a legalidade e a compulsoriedade da vacinação.

Vacinação compulsória: o conflito entre o individual e o coletivo

No campo jurídico, para solucionarmos as relações ou os conflitos existentes entre a saúde pública e os direitos humanos, será necessário equilibrar os direitos individuais (liberdade individual e autodeterminação) e os direitos coletivos (responsabilidade e interesse comunitários).
O debate que ocorre entre o individual e o coletivo, entre restringir liberdades (capacidade de autodeterminar-se frente à vacinação) e garantir saúde coletiva (proteger a saúde de todos com a vacinação) há de ser considerado um conflito de posições contrárias?

Para solucionar a questão, é necessário esclarecer que algumas situações são admitidas para restringir direitos, sem que, para isso, ocorra transgressão dos direitos humanos. A busca pelo bem comum é uma das formas de restringir a capacidade de se autodeterminar ${ }^{37}$.

Não há negação sobre as liberdades individuais. 0 filósofo Kant ${ }^{38}$ considera que a pessoa tem livre capacidade de agir, de estabelecer um fim para si mesmo. Essa acepção decorre da autonomia, da capacidade de autodeterminação, da livre manifestação da vontade. E nesse sentido, realmente a CF garante como fundamental o direito de autodeterminar-se. A liberdade individual é uma conquista humana inigualável. Possui valor fundamental como conquista de direitos e garantias individuais.

Não podemos esquecer, contudo, que o mesmo diploma legal garante como fundamental outros direitos - como o direito à saúde. Quando os preceitos garantidos por outros direitos entram em conflito na norma constitucional, inegavelmente há que fazer uma ponderação entre eles, de forma a estabelecer uma ordem a ser respeitada para a solução da situação concreta ${ }^{39}$.

De forma ilustrativa podemos considerar a situação do indivíduo que não gosta de usar máscara facial protetiva enquanto passeia na praia ou da pessoa pública que prefere fazer suas aparições públicas em contato com seus admiradores ou correligionários sem o uso da máscara, vigente norma que impõe o uso desse equipamento de proteção para tais situações. Nesses casos, a sua liberdade individual de autodeterminação sofre restrição justificada em face do interesse coletivo da saúde ${ }^{40}$.

Essas situações são exemplos práticos e cotidianos da aplicação do critério da proporcionalidade, que conta com técnicas da adequação, da exigibilidade e da ponderação para solucionar conflitos entre direitos fundamentais ${ }^{41}$. A proporcionalidade fará o sopesamento do conflito e dará a justa medida e a adequação do resultado ${ }^{42}$. A ponderação irá otimizar a coexistência desses direitos, de forma tal, que o Estado poderá limitar (ou restringir) uma garantia constitucional em prol de outra.

Imaginemos agora casos que envolvam risco à saúde e à integridade física de toda uma nação ou da humanidade. Se para os casos acima mencionados a proporcionalidade atua para ponderar os direitos e princípios fundamentais, não há que ser diferente na questão da vacinação obrigatória.

A declaração de estado pandêmico da COVID-19 é manifestamente uma situação autorizadora da restrição do direito de liberdade individual quando o que está em risco é a saúde coletiva, visto que ao ponderarmos entre a segurança coletiva e a integridade individual, prevalecerá o direito que ampara a saúde de todos.

O cidadão no seu âmbito privado (no seu núcleo familiar) não é obrigado a usar as máscaras faciais de proteção, mas em 
coletividade o é, pois o risco de contaminar-se e de contaminar o próximo é maior quando não respeitada a medida profilática ${ }^{40}$.

$\mathrm{Na}$ vacinação, a motivação da obrigatoriedade é semelhante.

Vacinar-se significa diminuir riscos, uma vez que a produção de anticorpos agirá contra os agentes patogênicos causadores de infecções. As vacinas são a principal forma de prevenção contra diversas doenças, porque não protegem apenas o indivíduo que foi imunizado, mas protegem toda a comunidade, pois aquele indivíduo, ao não adoecer, também não se torna transmissor da doença (COVID-19), transmitindo-a às demais pessoas. Quanto mais pessoas forem imunizadas, maior a chance de erradicação (ou controle) da doença ${ }^{43}$. Há estudos específicos em relação ao tema que estabelecem, inclusive, percentuais de vacinação da população para que se surta o efeito de proteção coletiva.

Quanto menor o número de pessoas imunizadas, maior será a chance de a doença se propagar na comunidade. Corrobora essa afirmação a volta recente da circulação do sarampo. A queda na adesão da vacinação contra o sarampo, que estava erradicado no Brasil desde 1989, tem sido apontada como a responsável pela volta do sarampo em várias regiões ${ }^{44}$.

A medida restritiva de liberdade individual para imposição da vacinação em prol da coletividade, encontrada neste estudo, reitera o antagonismo entre autonomia privada e decisão coletiva, legitimando o Estado a equacionar o conflito, tomando medida que imponha a obrigatoriedade da vacinação contra a COVID-19.

Há, porém, diferença entre o uso obrigatório de máscara facial nas situações previstas em lei e a compulsoriedade da vacina. A vacina, por mais segura que seja, ainda assim representa risco, podendo gerar eventos adversos após sua aplicação e justamente é essa a questão (entre outras) que deveria ser considerada como um aspecto a ser monitorado no plano de vacinação ou em eventual normatização ou portaria.

Sendo assim, para que o sacrifício ao direito individual seja o menor possível e que se evite atingir outros direitos, como a vida e a saúde, por conta da vacinação compulsória, seria recomendável haver, no plano de vacinação a ser implementado, o monitoramento temporário e outras formas de medidas compensatórias de danos ${ }^{45}$.

\section{Plano de imunização contra a COVID-19}

A forma pela qual se deve proceder à vacinação em âmbito nacional é por meio da incorporação da nova tecnologia no PNI ${ }^{46}$.

As vacinas aplicadas na rotina da população são aquelas constantes do calendário oficial de vacinação pelo PNI - com cobertura atual de 19 imunizantes e prevenção de 20 doenças ${ }^{46,47}$. O PNI, que é referência em política pública, foi formulado em 1973, institucionalizado em 1975 e vinculado ao Ministério da Saúde.

O planejamento e a cobertura vacinal por ele oferecidos têm o caráter contínuo de imunização e, justamente por isso, o seu sucesso, cujo objetivo da política pública é não excluir ninguém da vacinação em massa. Por esse programa, o controle de doenças, em todas as faixas etárias, torna-se possível.

As novas vacinas que surgem no cenário científico, após aprovação da Anvisa, são incorporadas ao $\mathrm{PNI}^{48}$.

No contexto atual, para se adequar ao PNI, o governo federal por meio do Ministério da Saúde deve integrar esforços, apoiar e buscar atividades e propostas para a inovação tecnológica das futuras vacinas da COVID-19. Mais que isso, deve formalizar o planejamento e a normativa que vise integrar a vacinação da doença, esquematizar a população-alvo e as etapas e datas de vacinação. Deve provisionar o número de material a ser utilizado, as doses de imunizantes (considerando as duas doses completas por indivíduos, se for o caso), a estimativa de gastos para aquisição envolvendo todas as etapas da vacinação. E por fim, como esclareceu Dalcomo ${ }^{49}$, deve garantir que a vacinação contra a COVID-19 não interfira e não prejudique a vacinação oficial do calendário em vigor. Não é admissível, com isso, que a vacinação contra a COVID-19 utilize material destinado a outras campanhas, causando um prejuízo às outras coberturas vacinais.

Cedendo à pressão judicial, política e da população, em $1^{\circ}$ de dezembro de 2020, dias depois de apresentar a defesa no TCU impugnando o acórdão que recomendou a elaboração do plano, o Ministério da Saúde (via governo federal) apresentou um plano preliminar de vacinação $0^{50,51}$.

O governo do estado de São Paulo, cujas medidas vêm sendo amparadas pela competência concorrente e pela lei de enfrentamento ao novo coronavírus que concede às autoridades locais a competência para ações emergência em saúde (artigos $3^{\circ}$ e $7^{\circ}$ da Lei $n^{\circ}$ 13.979/2020) ${ }^{21}$, lançou seu próprio plano de vacinação em 7 de dezembro, o Plano Estadual de Imunização de São Paulo (PEI) ${ }^{52}$.

Logo após o plano estadual ser apresentado, o planejamento do governo federal, chamado Plano de Operacionalização da Vacinação ${ }^{35}$ contra a COVID-19, foi entregue ao STF (antes do julgamento das ações de inconstitucionalidade) e lançado oficialmente em 16 de dezembro de 2020.

Em que pese a tardia elaboração do plano nacional e as falhas nas informações, sua existência é necessária, tal qual ocorreu com a campanha de combate à influenza A H1N1.

Apenas para análise comparativa, o Ministério da Saúde, em 2009, por meio da Nota Técnica $n^{\circ}$ 05/2010, introduziu no calendário oficial a vacinação de influenza A H1N1 (declarada pandêmica pela OMS) ${ }^{53}$. Não houve, naquela oportunidade, objeção do governo federal quanto ao planejamento vacinal. Ao contrário, ao introduzir a nova vacina, criou estratégia de vacinação contra o vírus da gripe, detalhou as etapas de vacinação, esclareceu a providência para aquisição das vacinas e garantiu o acesso universal à imunização/saúde (garantia constitucional) através da vacinação gratuita nas Unidades Básicas de Saúde (UBS) geridas pelo SUS ${ }^{54}$. A vacinação do vírus influenza A H1N1 continua ativa e incorporada no PNI e acreditamos, diante do que estudamos, que essa possibilidade não poderá ser descartada em relação à vacinação contra a COVID-19. 
Com esses dois planos de imunização apresentados, o PEI do estado de São Paulo52 e o Plano Nacional de Operacionalização ${ }^{35}$ do governo federal, temos nas entrelinhas as seguintes orientações: no primeiro, a compulsoriedade da vacinação; no segundo, a voluntariedade da vacinação.

Esse posicionamento diverso retrata a total altercação e a verdade na disputa entre o governador do estado de São Paulo e o presidente da república na medição de forças políticas. Ao que parece, a escolha pela compulsoriedade da vacinação está alicerçada em evidência científica, ao passo que a voluntariedade está amparada em crenças pessoais sem embasamento científico, como aquela que relaciona o uso do imunizante com o efeito adverso de transformação do ser humano em jacarée ${ }^{55}$.

\section{Imunização contra a COVID-19: a questão política}

A Lei $n^{\circ} 6.259$, de 30 de outubro de 1975, dispõe sobre as ações de Vigilância Epidemiológica, sobre o PNI e sobre as normas de notificação compulsória de doenças e esclarece que compete ao Ministério da Saúde coordenar as ações relacionadas com o controle das doenças transmissíveis, orientar quanto à Vigilância Epidemiológica e o programa de imunizações (artigo $\left.1^{\circ}\right)^{56}$.

Pela lei, cabe ao Ministério da Saúde elaborar o PNI, que definirá a estratégia e a cobertura de vacinas, inclusive as de caráter obrigatório (artigo $3^{\circ}$, caput e parágrafo único). O PNI já existe ${ }^{48}$ e está em uso no país desde 1975, portanto, no momento é papel do Ministério da Saúde elaborar o plano ou estratégia técnica (por portaria ou nota técnica ou informe técnico) que vise incorporar os novos imunizantes ao programa nacional.

Como se observa no texto legal, a possibilidade de compulsoriedade de algumas vacinas já não é novidade, e a vacinação infantil constante do calendário oficial do PNI é o típico exemplo. Em caso de não vacinação, o Estatuto da Criança e do Adolescente (ECA) prevê a punição dos responsáveis, pais ou tutores/guardiões, cujo dever é cuidar dos menores, garantindo-lhes, entre outras coisas, a saúde. A vacinação obrigatória, sob a ótica do $\mathrm{ECA}^{57}$, tem a finalidade de preservação da saúde (artigo 14), e foi exatamente isso que o STF acabou de definir no tema 1.103 de Repercussão Geral (leading case: ARE 1267879)31,32,33. De outra forma, também ela é obrigatória em certas viagens internacionais. A OMS orienta que, havendo a exigência do país de destino, será obrigatório apresentar o Certificado Internacional de Vacinação ou Profilaxia (CIVP). Nestes casos, a pessoa pode se recusar, mas não será permitida sua entrada no país em questão ${ }^{58}$. Até mesmo no Brasil, em algumas viagens internas, dependendo da região a ser visitada, existe a obrigatoriedade de vacinação.

Ainda sobre o tema, as vacinas constantes do Calendário de Vacinação Militar são obrigatórias visando a imunização dos militares das Forças Armadas (artigo $1^{\circ}$, parágrafo único da Portaria Normativa $\mathrm{n}^{\circ} 94$, de 4 de novembro de 2020), figurando como condição necessária para matrícula nos cursos previstos nos Sistemas de Ensino das Forças Armadas e aptidão para o Serviço Ativo por ocasião das inspeções de saúde (artigo $\left.4^{\circ}\right)^{59}$.
Com isso, a compulsoriedade de algumas vacinas não é novidade no mundo jurídico, na sociedade e até mesmo na vida castrense. Não sendo uma medida apartada da realidade, já vivenciada por muitos, por que haveria hesitação quanto à obrigatoriedade?

O presente artigo foi escrito antes do início da vacinação no país e, durante o processo de revisão às cegas pelos pares, iniciou-se a imunização vacinal da população brasileira.

Já nas primeiras semanas, foi possível observar a notória adesão das pessoas à vacinação oferecida pelo SUS, a indicar que a compulsoriedade da vacina contra a COVID-19, assim como a da vacinação das crianças e adolescentes, deverá atingir mais diretamente somente aquela parcela da população que se identifica com movimentos antivacinais ou que se nega a reconhecer a segurança e a eficácia das vacinas disponíveis para o novo coronavírus, contra toda evidência científica produzida. 0 assunto, entretanto, merece estudo apartado e complementar ao presente.

Bem esclareceu Lewandowski ${ }^{31,32,33}$, a pandemia de 2020 revelou aos brasileiros um novo cenário além de um vírus mortal. Não somente o vírus vitima a população em números de adoecimentos e mortes, mas também a inconsistência da governança, que se mostrou fraca frente à sua responsabilidade de assegurar os direitos fundamentais contemplados nos artigos $5^{\circ}, 6^{\circ}$ e 196 da CF. É de competência dos agentes públicos uma atuação forte e efetiva, por meio da implementação de políticas ou programas de combate à COVID-19. E para que tais medidas possam ser executadas, o momento exige a somatória de ações com a união e o planejamento conjunto de todos os governantes (governo federal e entes federados). Entretanto, em vez da união de forças governamentais, o Brasil foi invadido pela polarização alimentada por declarações e decisões do governo federal sem respaldo científico.

O discurso de posições radicais - de um lado o presidente da república e, de outro, o governador do estado de São Paulo - apenas resulta em consequências negativas, a ponto de fazer com que regulamentos e institutos jurídicos sejam desrespeitados ${ }^{60}$.

O governo federal, por meio do Ministério da Saúde, divulgou um plano preliminar ${ }^{50}$ logo após apresentar sua defesa na ação que the move o $\mathrm{TCU}^{30}$ e, apresentou o plano "definitivo" 35 quando do vencimento do prazo dado pelo STF nas ações de inconstitucionalidade ${ }^{31,32,33}$. Nesse intervalo entre um e outro plano do Ministério da Saúde, o governo do estado de São Paulo também apresentou um plano de vacinação ${ }^{52}$, este, porém, de âmbito estadual. Notadamente não há consenso entre os governantes.

A cooperação entre os entes federados com competência concorrente entre a União, os Estados e o Distrito Federal (norma constitucional - princípio do federalismo cooperativo) deveria ser seguida em busca da proteção e da defesa da saúde de todos, visando uma normatização única (senão única ao menos harmônicas e compatíveis entre si) a ser instituída e respeitada em prol dos mesmos objetivos.

O governo federal tem a função de planejar e promover, em caráter permanente, a defesa de todos os brasileiros e estrangeiros residentes no país contra as calamidades públicas, definir e 
coordenar sistemas de Vigilância Epidemiológica e Sanitária e participar na execução de ações de Vigilância Epidemiológica e outras ocorrências que possam escapar do controle da direção estadual do SUS ou que representem risco de disseminação nacional (leitura conjunta dos artigos 21, XVIII e $198 \mathrm{da} \mathrm{CF/88} \mathrm{e} \mathrm{artigo} \mathrm{16,} \mathrm{III,}$ da Lei $n^{\circ} 8.080 / 1990$ e do Decreto Legislativo $\left.n^{\circ} 6 / 2020\right)^{61,62}$.

Em contrapartida, não é função do governo federal pautar-se por posicionamentos políticos particulares ou partidários e até mesmo ideológicos para rejeitar ou aceitar determinada vacina e seus insumos. A briga pela vacina $A$ ou vacina $B$ não é atribuição governamental, nem federal nem estadual.

É possível constatar pela simples observação que as divergentes posições das lideranças governamentais causam incerteza, desconfiança e insegurança quanto à importância da imunização vacinal. As estratégias dos agentes políticos durante a crise sanitária influenciam o comportamento e as reações da população, inclusive quanto à percepção de eficácia do governo em lidar com a pandemia. A polarização da sociedade é um reflexo dessas condutas ${ }^{63}$.

As razões ou os motivos particulares de entendimentos opostos sobre os imunizantes expondo em discurso público a rejeição de um ou algum imunizante não são atribuições políticas do presidente da República e nem tampouco dos governadores.

Julgar o imunizante eficiente e eficaz é atribuição da comunidade científica e das agências estatais competentes, seguindo as normas e princípios de bioética e as práticas de medicina baseada em evidências.

Aceitar e regulamentar a entrada do imunizante no país é atribuição da Anvisa. Sobre esse assunto, a Instrução Normativa $n^{\circ}$ 77 , de 17 de novembro de 2020 , dispõe sobre o procedimento de submissão contínua de dados técnicos para o registro de vacinas COVID-19 e estabelece que o procedimento é diferenciado para se analisar os dados referentes às vacinas na medida em que forem gerados e apresentados à agência (artigo $2^{\circ}$, IV). Após a submissão contínua, havendo a conclusão e avaliação de qualidade, eficiência e segurança (estas apenas reiteradas pela Anvisa), será possível proceder ao registro formal na agência (artigo $9^{\circ}$, caput) ${ }^{64}$.

A inovação na tecnologia da produção de vacinas é regulada pelas normas de Boas Práticas de Fabricação (BPF), Boas Práticas de Laboratório (BPL) e Boas Práticas Clínicas (BPC). No Brasil, a agência reguladora que inspeciona o cumprimento das boas práticas é a Anvisa ${ }^{65}$. Com isso, os imunizantes, cumprindo as exigências e normas da Anvisa, poderão adentrar o território nacional, inclusive para posterior comercialização.

Vale esclarecer que, excepcionalmente, a própria Lei Federal $n^{\circ} 13.979 / 2020$ prevê a autorização temporária para a importação e distribuição de vacina, sem registro na Anvisa, desde que consideradas essenciais para auxiliar no combate à pandemia do novo coronavírus e que estejam registradas ao menos por uma autoridade sanitária estrangeira (elencadas pelo texto legal artigo $3^{\circ}$, VIII) $)^{21}$.
Com isso, num procedimento normal, é incumbência da Anvisa solucionar pendências sobre os protocolos de autorização das vacinas contra a COVID-19 e, por outro lado, é incumbência do governo federal (ou do estadual, conforme as permissões legais) elaborar o plano de vacinação que integre o PNI já existente, adquirir os imunizantes e demais insumos necessários e, finalmente, efetivar a imunização. Contudo, pairam dúvidas sobre a governança legítima, quer federal quer estadual.

Ao extrapolar ou omitir suas ações e competências, podem os governantes atrasar o planejamento vacinal e gerar sensação de insegurança na população? A resposta nos parece positiva e a instauração da chamada Comissão Parlamentar de Inquérito da Pandemia junto ao Senado Federal por determinação do STF (Mandado de Segurança n $\left.{ }^{\circ} 37.760 / D F\right)^{66}$, durante o mês de abril de 2021, enquanto este material era revisado, revela a complexidade em termos de agentes e interesses políticos envolvidos na atuação do Estado frente à crise sanitária global e em especial na condução do processo de aquisição de vacinas e imunização da população brasileira.

Esta população influenciada (polarizada $)^{60}$ por seus governantes tem se dividido em manifestações (principalmente nas redes sociais) pró e contra a atuação do governo federal e a compulsoriedade da vacina, o que remete à lembrança do episódio da Revolta das Vacinas.

$\mathrm{Na}$ ocasião, por volta do ano de 1904, houve a revolta da população em razão de uma lei (encabeçada pelo sanitarista Oswaldo Cruz) que obrigava a vacinação contra a varíola ${ }^{67,68}$. A campanha daquela época, porém, foi realizada sem a devida informação direito hoje respeitado, consagrado e fiscalizado pelos princípios da transparência e informação. 0 fato histórico resultou na não submissão da população à vacinação obrigatória e, até o final da década de 1910, a doença esteve presente no país, valendo registrar que sua erradicação definitiva (mundial) foi certificada apenas em 1979/80 pela OMS ${ }^{69,70}$.

A história por vezes se repete, sabemos, mas o que pretendemos é a não repetição de um movimento (naquela época social, hoje político) que possa atrapalhar as acertadas decisões de enfrentamento à COVID-19.

A vacinação é a medida acertada, à luz das evidências científicas colhidas até o presente. 0 conhecimento científico se valida pelo método que emprega para buscar as respostas e a lei adotou a fundamentação científica como critério de decisão governamental. Não politizar a vacinação é a solução para se alcançar a medida acertada e a maior parte da população brasileira, ao que parece, compreendeu a necessidade da vacinação no combate à COVID-19.

\section{CONCLUSÕES}

O direito à saúde no Brasil alcança as ações e serviços de prevenção a doenças e agravos à saúde. A CF de 1988 consagra a saúde (e a imunização) como direito a ser garantido pelo Estado, disponível a todos por meio do SUS. 
O direito à vacinação vem sendo efetivado pelo PNI, que disponibiliza vacinas à população em número superior ao recomendado pela OMS. A conquista da adesão ao plano de vacinação e a cultura da imunização ocorreram ao longo de muitos anos, ao longo de uma trajetória de políticas de saúde que passaram a garantir à população informação adequada e segurança dos imunizantes oferecidos pelo Ministério da Saúde.

Colocar essa conquista da saúde no seio de disputas políticas faz brotar a desconfiança em relação à segurança e à eficácia das vacinas do PNI e contra a COVID-19. Resulta, novamente, em processo de desinformação pública e, neste caso, ainda fomentado por declarações de agentes políticos, sem lastro em evidências científicas.

Não interessa quem vai ganhar a corrida da vacina, se o governo federal ou o paulista, nem quem vai faturar eleitoralmente com isso, o que interessa é que essa disputa política não prejudique a população brasileira, especialmente diante da necessidade de decisões normativas por parte dos governantes (presidente, governadores e prefeitos) em favor da compulsoriedade da vacinação, cuja legitimidade demonstrou-se possível, havendo imunizantes seguros e eficazes, como são aqueles aprovados pelas agências estatais competentes.

\section{REFERÊNCIAS}

1. Lai CC, Shin TP, Ko W, Tang HJ, Hsueh PR. Severe acute respiratory syndrome coronavirus 2 (SARS-CoV-2) and coronavirus disease-2019 (COVID-19): the epidemic and the challenges. Int J Antimicrob Agents. 2020;55(3):1-9. https://doi.org/10.1016/j.ijantimicag.2020.105924

2. Pan American Health Organization - PAHO. Folha informativa: COVID-19 (doença causada pelo novo coronavírus). Washington: Pan American Health Organization; 2020[acesso 28 nov 2020]. Disponível em: https: / /www. paho.org/bra/index.php?option=com_ content\&view $=$ article\&id $=6101$ : covid $19 \&$ Itemid $=875$

3. World Health Organization - WHO. WHO director-general's opening remarks at the media briefing on COVID-19. Speeches. 11 mar 2020[acesso 26 nov 2020]. Disponível em: https://www.who.int/director-general/speeches/detail/ who-director-general-s-opening-remarks-at-the-media-brief ing-on-covid-19---11-march-2020

4. Johns Hopkins University - JHU. COVID-19 dashboard by the center for systems science and engineering (CSSE). Baltimore: Johns Hopkins University; 2021 [acesso 7 jan 2021]. Disponível em: https://coronavirus.jhu.edu/map.html

5. Ministério da Saúde (BR). Boletim coronavírus. Brasília: Ministério da Saúde; 2021[acesso 6 jan 2021]. Disponível em: https://www.coronavirus.ms.gov.br/?cat=5

6. Worldmeter. World population. Pudong: Dadax; 2021[acesso 7 jan 2021]. Disponível em: https://www.worldometers. info/world-population/

7. Worldmeter. Population by country. Pudong: Dadax; 2021[acesso 7 jan 2021]. Disponível em: https://www.worldometers.info/world-population/ population-by-country/

8. Pan American Health Organization - PAHO. Folha informativa COVID-19: escritório da OPAS e da OMS no Brasil. Washington: Pan American Health Organization; 2020[acesso 15 dez 2020]. Disponível em: https://www.paho.org/pt/covid19

9. World Health Organization - WHO. Coronavirus disease (COVID-19): vaccines. Geneva: 2020[acesso 14 dez 2020]. Disponível em: https: //www.who.int/news-room/q-adetail/coronavirus-disease-(covid-19)-vaccines?adgroup survey $=\{$ adgroupsurvey $\}$ \&gclid $=$ CjOKCQiA2uH-BRCCARIsA
Eeef3k7Uw3aeGANKnDa9xk0FmrTZEPteigPjvc688gOEI nLIl6X_EqkfhAaArxqEALw_wcB

10. World Health Organization - WHO. Countries. Geneva: 2020[acesso 26 nov 2020]. Disponível em: https://www.who.int/countries/

11. Instituto Butantan. Vacina do Butantan chega à fase final. Notícias. 23 nov 2020[acesso $11 \mathrm{dez} 2020$ ]. Disponível em: https://butantan.gov.br/noticias/ vacina-do-butantan-chega-a-fase-final

12. Fundação Oswaldo Cruz - Fiocruz. Como é feita a vacina candidata da COVID-19 da Universidade de Oxford/ AstraZeneca? Rio de Janeiro: Fundação Oswaldo Cruz; 2020[acesso $11 \mathrm{dez}$ 2020]. Disponível em: https://portal. fiocruz.br/pergunta/como-e-feita-vacina-candidatada-covid-19-da-universidade-de-oxford/astrazeneca

13. Fundação Oswaldo Cruz - Fiocruz. Vacinas contra COVID-19. Rio de Janeiro: Fundação Oswaldo Cruz; 2020[acesso 11 dez 2020]. Disponível em: https://portal.fiocruz.br/ vacina-covid-19-ensaios-clinicos

14. Agência Nacional de Vigilância Sanitária - Anvisa. Vacinas COVID-19: fique por dentro do mapa das vacinas em teste no Brasil. Notícias. 14 set 2020[acesso 5 dez 2020]. Disponível em: https://www.gov.br/anvisa/pt-br/assuntos/ noticias-anvisa/2020/fique-por-dentro-do-mapa-das-vaci nas-em-teste-no-brasil

15. Pan American Health Organization - PAHO. Regulamento sanitário internacional (RSI). Washington: Pan American Health Organization; 2020[acesso 27 nov 2020]. Disponível em: https: / /www.paho.org/bra/index.php?option=com_con tent\&view=article\&id=5847: regulamento-sanitario-internaci onal-rsi\&ltemid $=812$

16. Brasil. Decreto $N^{\circ} 395$, de 9 de julho de 2009. Aprova o texto revisado do regulamento sanitário internacional, acordado na $58^{\mathrm{a}}$ Assembléia Geral da Organização Mundial de Saúde, em 23 de maio de 2005. Diário Oficial União. 10 jul 2009.

17. Brasil. Decreto $N^{\circ} 10.212$, de 30 de janeiro de 2020. Promulga o texto revisado do regulamento sanitário internacional, acordado na $58^{\mathrm{a}}$ Assembleia Geral da Organização Mundial de Saúde, em 23 de maio de 2005. Diário Oficial União. 31 jan 2020. 
18. Câmara dos Deputados Federais. Projeto de lei $\mathrm{N}^{\circ}$ 9, de 3 de fevereiro de 2020. Dispõe sobre as medidas para enfrentamento da emergência de saúde pública de importância internacional decorrente do coronavírus. Proposições Web. 3 fev 2020[acesso 26 nov 2020]. Disponível em: https://www.camara.leg.br/ proposicoesWeb/ prop_mostrarintegra;jsessionid= E5D34B26717B978E92D944DF0FA5AB69.

proposicoesWebExterno1?codteor= 1853941\&filename $=\mathrm{PL}+23 / 2020$

19. Câmara dos Deputados Federais. Projeto de lei $N^{\circ} 23$, de 4 fevereiro de 2020. Dispõe sobre as medidas para enfrentamento da emergência de saúde pública de importância internacional decorrente do coronavírus responsável pelo surto de 2019. Proposições Web. 4 fev 2020[acesso 26 nov 2020]. Disponível em: https://www.camara.leg.br/proposicoesWeb/ fichadetramitacao?idProposicao $=2236343$

20. Brasil. Projeto de lei № 23, de 5 fevereiro de 2020. Dispõe sobre as medidas para enfrentamento da emergência de saúde pública de importância internacional decorrente do coronavírus responsável pelo surto de 2019. Atividade Legistativa. 5 fev 2020[acesso 26 nov 2020]. Disponível em: https://www25.senado.leg.br/web/atividade/materias/-/ materia/140490

21. Brasil, Lei $N^{\circ} 13.979$, de 6 de fevereiro de 2020. Dispõe sobre as medidas para enfrentamento da emergência de saúde pública de importância internacional decorrente do coronavírus responsável pelo surto de 2019. Diário Oficial União. 7 fev 2020.

22. Brasil. Decreto de 16 de abril de 2020. Exoneração Luiz Henrique Mandetta do cargo de Ministro da Saúde. Diário Oficial União. 17 abr 2020.

23. Conselho Nacional de Secretarias Municipais da Saúde - CONASEMS. Nelson Teich é nomeado novo Ministro da Saúde. Notícias. 16 abr 2020[acesso 27 nov 2020]. Disponível em: https://www.conasems.org.br/ nelson-teich-e-nomeado-para-ministro-da-saude/

24. British Broadcast Company - BBC. Ministro da Saúde Nelson Teich pede demissão menos de um mês depois de assumir. BBC News. 15 maio 2020[acesso 27 nov 2020]. Disponível em: https://www.bbc.com/portuguese/brasil-52683285

25. Pedrozo J. Pazuello é nomeado oficialmente como ministro da Saúde interino. Gazeta do Povo. 3 jun 2020[acesso 28 nov 2020]. Disponível em: https://www.gazetadopovo. com.br/republica/breves/pazuello-ministro-dasaude-interino/

26. Redação. Pazuello tomará posse na quarta como ministro da Saúde após período como interino. IstoÉ. 14 set 2020[acesso 29 nov 2020]. Disponível em: https://istoe.com.br/pazue llo-tomara-posse-na-quarta-como-ministro-da-saude-apos-p eriodo-como-interino/

27. Verdélio A. Ministério da Saúde muda formato de divulgação de dados de COVID-19. Agência Brasil. 8 jun 2020[acesso 28 dez 2020]. Disponível em: https://agenciabrasil.ebc. com.br/saude/noticia/2020-06/ministerio-da-saude-muda-f ormato-de-divulgacao-de-dados-de-covid-19
28. Universo OnLine - UOL. MP dá $72 \mathrm{~h}$ para Ministério da Saúde explicar mudança na divulgação de mortes. UOL Coronavírus. 6 jun 2020[acesso 30 dez 2020]. Disponível em: https://noticias.uol.com.br/saude/ultimas-noticias/ redacao/2020/06/06/mp-da-72h-para-ministerio-da -saude-explicar-mudanca-na-divulgacao-de-mortes. htm?cmpid=copiaecola

29. Parreira $M$, Rodrigues $M$. Governo obedece à ordem do STF, e Ministério da Saúde volta a divulgar dados completos da COVID. G1 Política. 9 jun 2020[acesso $30 \mathrm{dez}$ 2020]. Disponível em: https://g1.globo.com/politica/ noticia/2020/06/09/ministerio-da-saude-volta-a-divulga r-no-site-oficial-dados-acumulados-da-covid-19.ghtml

30. Secom TCU. TCU determina à Casa Civil que elabore plano de imunização do Brasil. Notícias. 21 ago 2020[acesso em 30 nov 2020] Disponível em: https://portal.tcu.gov.br/ imprensa/noticias/tcu-determina-a-casa-civil-que-elaboreplano-de-imunizacao-do-brasil.htm

31. Lewandowski R. Ação direita de inconstitucionalidade № 6.586 Distrito Federal. Brasília: Supremo Tribunal Federal; 2020[acesso 28 dez 2020]. Disponível em: http://www.stf.jus.br/arquivo/cms/noticiaNoticiaStf/ anexo/adi6586despacho.pdf

32. Lewandowski R. Ação direita de inconstitucionalidade № 6.587 Distrito Federal. Brasília: Supremo Tribunal Federal; 2020[acesso 29 dez 2020]. Disponível em: http://www.stf.jus.br/arquivo/cms/noticiaNoticiaStf/ anexo/adi6587despacho.pdf

33. Supremo Tribunal Federal - STF. Ministro Lewandowski pede informações ao presidente da República sobre vacinação. Notícias. 23 out 2020[acesso 30 nov 2020]. Disponível em: http://www.stf.jus.br/portal/cms/verNoticiaDetalhe. asp?idConteudo $=453974$

34. Valente F. Para Lewandowski, União tem o dever de usar vacinas contra a COVID-19. Boletim de Notícias Conjur. 24 nov 2020[acesso 26 nov 2020]. Disponível em: https://www.conjur.com.br/2020-nov-24/lewandowski-un iao-dever-usar-vacinas-covid

35. Ministério da Saúde (BR). Plano nacional de operacionalização da vacinação contra a COVID-19. Brasília: Ministério da Saúde; 2020[acesso 12 dez 2020]. Disponível em: https://download.uol.com.br/files/2020/12/89110721 5_2020_12_11_plano_de_vacinacao_covid19_revisado.pdf

36. Barroso R. Possibilidade dos pais deixarem de vacinar os seus filhos, tendo como fundamento convicções filosóficas, religiosas, morais e existenciais. Brasília: Supremo Tribunal Federal; 2020[acesso 2 jan 2020]. Disponível em: http://www.stf.jus.br/portal/ jurisprudenciaRepercussao/ verAndamento Processo.asp?incidente $=5909870$ \&numero Processo $=1267879$ \& classeProcesso $=$ ARE\&numeroTema $=1103$

37. Limal YOR, Costal EA. Regulamento sanitário internacional: emergências em saúde pública, medidas restritivas de liberdade e liberdades individuais. Vigil Sanit Debate. 2015;3(1):10-18. https://doi.org/10.3395/2317-269x.00266

38. Kant I. Metafísica dos costumes: introdução à doutrina da virtude. São Paulo: Edipro; 2012. 
39. Gavião Filho AP. Colisão de direitos fundamentais, argumentação e ponderação. Porto Alegre: Advogado; 2011.

40. Abud CO, Souza LP. Uso obrigatório de máscara facial para conter a COVID-19 no Brasil: limitação legítima ao direito fundamental de autodeterminação. Vigil Sanit Debate. 2020;8(3):34-43. https://doi.org/10.22239/2317-269x.01651

41. Canotilho JJG. Direito constitucional e teoria da constituição. 7a ed. Coimbra: Almedina; 2003.

42. Rezek CN. O princípio da proporcionalidade no estado democrático de direito. São Paulo: Lemos \& Cruz; 2004.

43. Santos HS. Vacinas. Goiânia: Biologia Net; 2020[acesso 1 dez 2020]. Disponível em: https://www.biologianet.com/ saude-bem-estar/vacinas.htm

44. Souza MTNF, Camargos KCO, Guimarães MR, Neves MRO, Alves CF. Impactos da hesitação vacinal na epidemiologia do sarampo. Brazil J Health Rev. 2020;3(2):1-3. https://doi.org/10.34119/bjhrv3n4-100

45. Campos AL. Uma análise bioética das decisões judiciais brasileiras sobre os eventos adversos pós-vacinação [tese]. Brasília: Universidade de Brasília; 2017[acesso 30 nov 2020]. Disponível em https://repositorio.unb.br/ handle/10482/23893

46. Ministério da Saúde (BR). Programa Nacional de Imunizações. Brasília: Ministério da Saúde; 2020[acesso 7 dez 2020]. Disponível em: https://portalarquivos.saude. gov.br/campanhas/pni/

47. Sociedade Brasileira de Imunizações - SBIM. Calendários de vacinação. Calendário SBIM. 27 nov. 2020[acesso 30 nov 2020]. Disponível em: https://sbim.org.br/ calendarios-de-vacinacao

48. Bordinhão R. O programa nacional de imunização brasileiro frente aos desafios para sua modernização e evolução. 24+Farma. 2020[acesso 2 dez 2020]. Disponível em: https://www.doisamaisfarma.com.br/noticias/o-p rograma-nacional-de-imunizacao-brasileiro-frente-aos -desafios-para-sua-modernizacao-e-evolucao/

49. Redação. No Roda Viva, especialistas esclarecem dúvidas sobre as vacinas contra a COVID-19. TV Cultura Notícias. $15 \mathrm{dez}$ 2020[acesso 18 dez 2020]. Disponível em: https: / /cultura.uol. com.br/noticias/14823_no-roda-viva-especialistas-esclarecemduvidas-sobre-as-vacinas-contra-a-covid-19-assista.html

50. Fundação Oswaldo Cruz - Fiocruz. Plano preliminar de vacinação contra a COVID-19 prevê quatro fases. Notícias e Artigos. 2 dez 2020 [acesso 4 dez 2020]. Disponível em: https://www.bio.fiocruz.br/index. $\mathrm{php} / \mathrm{br} /$ noticias/2090-plano-preliminar-de-vacinac ao-contra-a-covid-19-preve-quatro-fases

51. Associação Nacional de Especialistas em Políticas Publicas e Gestão Governamental - ANESP. Ex-ministros da saúde pedem: vacina para todos já! Notícias. 9 dez 2020[acesso 12 dez 2020]. Disponível em: http://anesp.org.br/ todas-as-noticias/vacina-para-todos-ja

52. Governo do Estado de São Paulo. Governo de SP inicia vacinação contra coronavírus em 25 de janeiro. Notícias Coronavírus. 7 dez 2020[acesso 8 dez 2020].
Disponível em: https://www.saopaulo.sp.gov.br/ noticias-coronavirus/governo-de-sp-inicia-vacinacao-con tra-coronavirus-em-25-de-janeiro/

53. Ministério da Saúde (BR). Informe técnico operacional: estratégia de vacinação contra o vírus de influenza pandêmico (H1N1) 2009. Brasília: Ministério da Saúde; 2010[acesso 29 nov 2020]. Disponível em: http: / /bvsms. saude.gov.br/bvs/publicacoes/estrategia_nacional_ vacinacao_influenza.pdf

54. Ministério da Saúde (BR). Estratégia de vacinação contra o vírus de influenza A H1N1. Brasília: Ministério da Saúde; 2010[acesso 29 nov 2020]. Disponível em: https: / /www. medicinanet.com.br/conteudos/revisoes/3005/nota tecnica_estrategia_de_vacinacao_contra_o_virus_de_ influenza_ah1n1.htm

55. Universo OnLine - UOL. Bolsonaro: se tomar vacina e virar jacaré não tenho nada a ver com isso. UOL Vídeos. $17 \mathrm{dez}$ 2020[acesso $30 \mathrm{dez}$ 2020]. Disponível em: https://www. youtube.com/watch? $v=$ IBCXkVOEH-8

56. Brasil. Lei $N^{\circ} 6.259$, de 30 de outubro de 1975. Dispõe sobre a organização das ações de vigilância epidemiológica, sobre o programa nacional de imunizações, estabelece normas relativas à notificação compulsória de doenças, e dá outras providências. Diário Oficial União. 31 out 1975.

57. Lamy M, Abud CO, Ferreira MR. Vacinação infantil: autonomia da vontade $x$ dever familiar. An Enc Nac Pós Grad. 2019;3(1):1-3.

58. Brasil. Tirar o certificado internacional de vacinação. Brasília: Saúde e Vigilância Sanitária; 2020[acesso 8 dez 2020]. Disponível em: https://www.gov.br/pt-br/servicos/ obter-o-certificado-internacional-de-vacinacao-e-profilaxia

59. Ministério da Defesa. Portaria normativa $N^{\circ} 94$, de 4 de novembro de 2020. Institui o calendário de vacinação militar. Diário Oficial União. 5 nov 2020.

60. Moraes E. COVID-19 e a epidemias da polarização. Linguasagem. 2020;35(1):1-21.

61. Brasil. Decreto legislativo $N^{\circ}$ 6, de 18 de março de 2020. Reconhece, para os fins do art. 65 da lei complementar $^{\circ} 101$, de 4 de maio de 2000, a ocorrência do estado de calamidade pública, nos termos da solicitação do presidente da república encaminhada por meio da mensagem $\mathrm{N}^{\circ} 93$, de 18 de março de 2020. Diário Oficial União. 20 mar 2019.

62. Brasil. Lei № 8.080, de 19 de setembro de 1990. Dispõe sobre as condições para a promoção, proteção e recuperação da saúde, a organização e o funcionamento dos serviços correspondentes e dá outras providências. Diário Oficial União. 20 set 1990.

63. Sobral F, Carvalho J, Tagowska U, Furtado LMGP, Grobman M. Melhor prevenir do que remediar: o sensemaking da liderança nos tempos da COVID-19. Rev Adm Pública. 2020;54(4):1-24. https://doi.org/10.1590/0034-761220200262x

64. Ministério da Saúde (BR). Instrução normativa № 77 , de 17 de novembro de 2020. Dispõe sobre o procedimento de submissão contínua de dados técnicos para o registro de vacinas COVID-19. Diário Oficial União. 18 nov 2020. 
65. Agência Nacional de Vigilância Sanitária - Anvisa. Entenda a certificação em boas práticas de fabricação. Brasília: Agência Nacional de Vigilância Sanitária; 2020[acesso 29 nov 2020]. Disponível em: https://www.gov.br/anvisa/ pt-br/assuntos/noticias-anvisa/2020/entenda-a-certificacao -em-boas-praticas-de-fabricacao

66. Barroso R. Mandado de segurança $N^{\circ} 37.760$ do Distrito Federal. Brasília: Supremo Tribunal Federal; 2021[acesso 18 jun 2021]. Disponível em: http://portal.stf.jus.br/ processos $/$ detalhe asp?incidente $=6129512$

67. Hochman G. Vacinação, varíola e uma cultura da imunização no Brasil. Cienc Saúde Coletiva. 2011;16(2):375-85. https: / / doi.org/10.1590/S1413-81232011000200002

68. Homma A, Martins RM, Leal MLF, Freire MS, Couto AR. Atualização em vacinas, imunizações e inovação tecnológica. Cienc Saúde Coletiva. 2011;16(2):445-58. https://doi.org/10.1590/S1413-81232011000200008
69. Pan American Health Organization - PAHO. Erradicação da varíola: um legado de esperança para COVID-19 e outras doenças. Washington: Pan American Health Organization; 2020[acesso 1 dez 2020]. Disponível em: https://www. paho.org/bra/index.php?option=com_content\&view=articl eqtid=6165:erradicacao-da-variola-um-legado-de-esperanca -para-covid-19-e-outras-doencas\&ltemid=812\#: : text $=8 \% 20$ de $\% 20$ maio\%20de $\% 202020$,pessoas $\% 20$ somente $\% 20$ no $\% 20$ s\%C3\%A9culo\%20XX.

70. Fundação Oswaldo Cruz - Fiocruz. Varíola: 40 anos do certificado de erradicação. Notícias e Artigos. $10 \mathrm{dez}$ 2019[acesso 6 dez 2020]. Disponível em: https://www. bio.fiocruz.br/index.php/br/noticias/1709-variola-40anos-do-certificado-de-erradicacao\#: : text=Baseado\%20 no\%20sucesso\%20obtido\%20na,no\%20pa\%C3\%ADs\%2C\%20 certificada\%20em\%201977

Contribuição dos Autores

Abud CO, Souza LP - Concepção, planejamento (desenho do estudo), aquisição, análise, interpretação dos dados e redação do trabalho. Os autores aprovaram a versão final do trabalho.

Conflito de Interesse

Os autores informam não haver qualquer potencial conflito de interesse com pares e instituições, políticos ou financeiros deste estudo.

Licença CC BY-NC atribuição não comercial. Com essa licença é permitido acessar, baixar (download), copiar, imprimir, compartilhar, reutilizar e distribuir os artigos, desde que para uso não comercial e com a citação da fonte, conferindo os devidos créditos de autoria e menção à Visa em Debate. Nesses casos, nenhuma permissão é necessária por parte dos autores ou dos editores. 